Jap. J. M. Sc. \& Biol., 16, 107-124, 1963

\title{
SOME FACTORS NECESSARY TO PRODUCE DIVISION CONDITIONS IN TETRAHYMENA PYRIFORMIS
}

\author{
YOSHIO WATANABE* \\ Biological Laboratory, Faculty of Education, Hosei University, Tokyo
}

(Received: November 29th, 1962)

The discovery of diverse methods for the synchronization of cell division have provided many interesting problems and developments in the solution of the mechanism of cell division. These methods have been developed primarily with the aim of permitting the study of cell life cycle events on a larger cell mass than possible with the use of more conventional procedures. The results reported earlier indicate that the biochemical changes during the division cycle undoubtedly vary greatly with cell type, with environmental conditions and with synchronizing systems (Campbell, A., 1957; Mazia, D., 1961 ; Prescott, D. M., 1961 ; Watanabe, Y., 1960 ; Zeuthen, E., 1958)

With the aim of demonstrating a generalized mechanism for multiplication of all cell types, two important facts must be recalled. First, artificially induced synchrony of cell division is initiated by a phase of recovery from specified imposed stress, therefore, induced division synchrony may not necessarily mean that the cells are synchronized with respect to all events of the cell life cycle in logarithmic growth phase. Second, most of the biochemical events during the cell life cycle may not be completely necessary for the succeeding cell division. The direct causal relations existing between biochemical changes and cell division must therefore be clarified.

In the present experiments, a ciliate protozoan, Tetrahymena pyriformis possessing several advantages for the biochemical analysis of cell division was employed. The investigations were designed to demonstrate the vital connection between adenosinetriphosphatase activity and cell division in the synchronized system, and to prove that synthesis of a specific protein is necessary for division of logarithmically growing cells.

\section{MATERIALS AND METHODS}

Standard culture conditions: Tetrahymena pyriformis strain $\mathrm{W}$ was grown under sterile conditions in $2 \%(\mathrm{~W} / \mathrm{V})$ proteose-peptone, enriched with $0.5 \%(\mathrm{~W} / \mathrm{V})$ yeast extract and $0.85 \%$ $(\mathrm{W} / \mathrm{V})$ dextrose in glass-distilled water. The cells were usually cultivated in $50 \mathrm{cc}$ Erlenmeyer flasks containing $10 \mathrm{cc}$ of medium. Under these conditions, the generation time averaged 3.5 hours at optimum temperature $\left(26^{\circ} \mathrm{C}\right)$. The stock cultures were kept in test tubes $(15 \times 155 \mathrm{~mm})$ containing $7 \mathrm{cc}$ of medium at $20^{\circ} \mathrm{C}$ and were usually renewed every month.

Washing of cells: When cells are transferred to a different medium, they are washed by 4 centrifugations with resuspension in the inorganic medium (mentioned later) under sterile conditions, unless otherwise specified.

Culture media: In addition to the proteose-peptone medium, an inorganic medium, a

* Present address : Department of Pathology, National Institute of Health, Tokyo. 渡辺 良雄（法政大学教育学部生物学教室） 
chemically defined synthetic medium and media deprived of some essential nutrients were employed. The inorganic medium $\left(\mathrm{NaCl} 100 \mathrm{mg}, \mathrm{KCl} 4 \mathrm{mg}, \mathrm{CaCl}_{2} 6 \mathrm{mg}\right.$, deionized water $\left.1000 \mathrm{cc}\right)$ was used for washing the cells and in the biochemical analysis.

The synthetic medium used was a modification of basal medium $2 \mathrm{~A}$ developed by Dewey et al. (Dewey, V. C., Parks, R. E., Jr., and Kidder, G. W., 1950) and Kidder and Dewey (Kidder, G. W. and Dewey, V. C., 1951). The composition of the synthetic medium is illustrated in Table 1. Under the optimum conditions in synthetic medium, the generation time averaged about 6.0 hours.

Table 1. Ingredients of the synthetic medium.

\begin{tabular}{|c|c|c|c|c|c|}
\hline \multicolumn{6}{|c|}{ Synthetic medium (Amounts in $r / c c$ ) } \\
\hline \multicolumn{2}{|l|}{ A-I } & \multicolumn{2}{|l|}{ B-I } & \multicolumn{2}{|l|}{$\mathrm{C}-\mathrm{I}$} \\
\hline DL-alanine & 220.0 & Calcium pantothenate & 0.20 & $\mathrm{MgSO}_{4}$ & 140.0 \\
\hline L-arginine & 420.0 & Nicotinamide & 0.20 & \multicolumn{2}{|c|}{$\mathrm{Fe}\left(\mathrm{NH}_{4}\right)_{2}\left(\mathrm{SO}_{4}\right)_{2} \cdot 6 \mathrm{H}_{2} \mathrm{O} 60.0$} \\
\hline L-aspartic acid & 240.0 & Pyridoxine $\cdot \mathrm{HCl}$ & 2.00 & $\mathrm{MnCl}_{2}$ & 1.0 \\
\hline Glycine & 20.0 & Pyridoxal $\cdot \mathrm{HCl}$ & 0.20 & $\mathrm{ZnCl}_{2}$ & 0.1 \\
\hline L-glutamic acid & 460.0 & Pyridoxamine $\cdot \mathrm{HCl}$ & 0.20 & $\mathrm{CaCl}_{2}$ & 30.0 \\
\hline L-histidine & 180.0 & Riboflavin & 0.20 & $\mathrm{CuCl}_{2}$ & 3.0 \\
\hline DL-isoleucine & 560.0 & Thiamine $\cdot \mathrm{HCl}$ & 2.00 & $\mathrm{FeCl}_{3}$ & 1.0 \\
\hline L-lysine & 680.0 & Biotin & 0.001 & $\mathrm{~K}_{2} \mathrm{HPO}_{4}$ & 100.0 \\
\hline DL-methionine & 500.0 & Choline chloride & 2.00 & $\mathrm{KH}_{2} \mathrm{PO}_{4}$ & 100.0 \\
\hline L-phenylalanine & 320.0 & & $\mathrm{Na}$ acetate & 100.0 \\
\hline L-proline & 500.0 & B-II & & \multicolumn{2}{|l|}{$\mathrm{D}-\mathrm{I}$} \\
\hline DL-serine & 780.0 & Pteroylglutamic acid & 0.20 & \multirow{2}{*}{ Dextrose } & \multirow{2}{*}{$5,000.0$} \\
\hline DL-threonine & 660.0 & B-III & & & \\
\hline L-tryptophan & 140.0 & \multirow{3}{*}{$\begin{array}{l}\text { DL-thioctic acid } \\
\text { Tween } 80\end{array}$} & 8.00 & \multicolumn{2}{|l|}{$\mathrm{E}-\mathrm{I}$} \\
\hline DL-valine & 320.0 & & 00.00 & Adenylic acid & 50.0 \\
\hline $\mathrm{F}-\mathrm{I}$ & & & & Cytidylic acid & 50.0 \\
\hline Uracil & 20.0 & & & Guanylic acid & 150.0 \\
\hline & & Adjusted to $\mathrm{pH} 6.6$ wi & $\mathrm{NaOH}$ & & \\
\hline
\end{tabular}

Main nutrients groups: A, amino acids; B, Vitamins ; C, inorganic chemicals ; D, dextrose; E, nucleotides; F, pyrimidine for RNA. In making up the medium concentrated stock solutions of various groups are prepared and mixed in propor proportions.

Media lacking each main group of single nutrient of the known nutritional factors in Table 1 were also employed. Log phase cells in complete medium were washed 4 or 5 times when being transferred to the nutrient-deprived of inorganic chemicals, the cells were washed with that medium in place of the usual inorganic medium.

Aliquots of the washed cell suspensions were always observed under the microscope, and identical aliquots were inoculated into the media after the absence of dead cells and fragments was confirmed.

Culture flasks: In most experiments, $50 \mathrm{ml}$ Erlenmeyer flasks containing $10 \mathrm{cc}$ of medium were employed. For ATPase assays, the cells were grown in $6 l$ French flasks containing $500 \mathrm{ml}$ of proteose-peptone medium.

Temperature-induced synchronous divisions: Synchronization in our strain has been achieved by application of basically the same technique as that reported by Scherbaum and Zeuthen (Scherbaum, O. and Zeuthen, E., 1954 ; Zeuthen, E. and Scherbaum, O., 1954). The system and the behaviors of synchronized cells grown in proteose-peptone medium are shown in Fig. 1. Log. phase cultures (about 15 hours after inoculation) were subjected to a controled temperature cycle: $i$. e., eight alternate 30 minute-exposures to temperatures of $34^{\circ} \mathrm{C}$ and $26^{\circ} \mathrm{C}$. After the heat- 


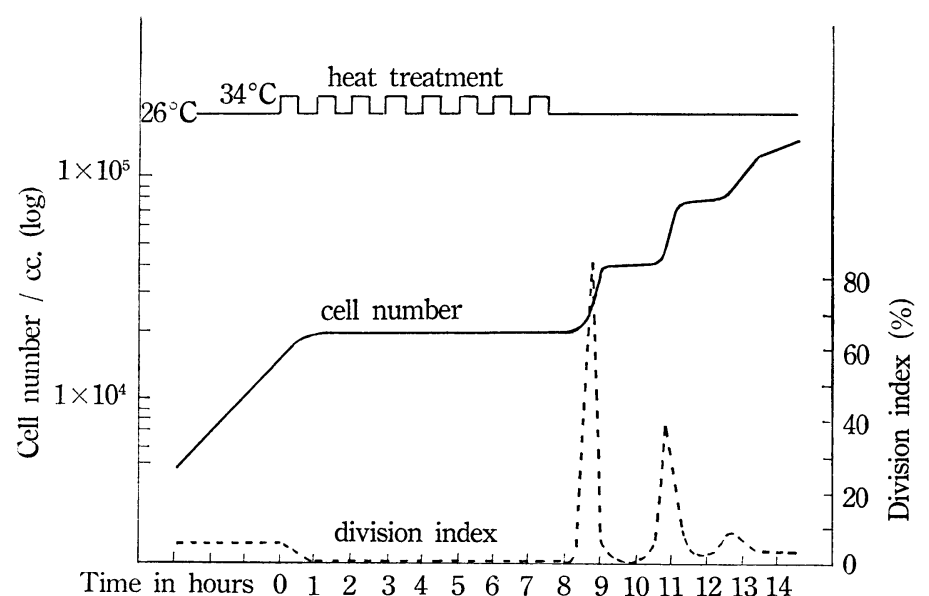

Fig. 1. Temperature-induced synchronous divisions in Tetrahymena pyriformis. The system of controlled temperature cycle is shown in the upper part. The continuous curve represents cell counts, and the broken curve represents division index.

treatment, the cultures were kept at the optimum temperature $\left(26^{\circ} \mathrm{C}\right)$. The first and the second synchronous divisions appeared at 75 minutes and about 190 minutes after the end of heat-treatment, the maximum division indices being nearly $85 \%$ and $40 \%$, respectively.

Cell counts: Samples, of $0.4 \mathrm{cc}$ each, were withdrawn at intervals by inserting the sterilized tuberculin syrings into the rubber stopper of the culture flask. Each sample was fixed with an equal volume of brilliant green fixative $(5 \%$ formol containing $0.01 \%$ of brilliant green). For counting the total numbers of cells and dividing cells per cc, a Fuchs-Rosenthal counting chamber was used.

Addition of sodium fluoride $(\mathrm{NaF})$ : The cells were cultivated in $50 \mathrm{cc}$ Erlenmeyer flask containing $9 \mathrm{ml}$ of proteose-peptone medium. After the controlled temperature cycle, $1 \mathrm{cc}$ of a $\mathrm{NaF}$ solution was added to the culture. Concentration of the agent employed is expressed as the final molar concentration in the culture medium. The effects of continuous or short exposures to $\mathrm{NaF}$ on synchronized cell divisions were investigated. After the cells had been in contact with the agent for a short period, they were transferred to the inorganic medium with 3 washings. It has always been observed that the cells given a short exposure recovered readily, but cell division was delayed to a greater or lesser extent. The effects of the inhibitor were measured by the delayed occurrence or complete lack of synchronous divisions.

Estimation of adenosinetriphosphatase (ATPase) activity: ATPase was assayed by estimating colorimetrically the inorganic phosphates liberated by the enzyme from ATP under the following conditions. About $10^{6}$ cells constituted an optimum sample for the estimation. Usually, 10 to $100 \mathrm{cc}$ samples were taken during the various growth phases and cooled in an ice bath for 5 minutes. The cells were washed 3 times with cold inorganic medium and the packed cells were suspended by the addition of cold distilled water to bring the volume up to $1.0 \mathrm{cc}$. They were then transferred to a glass homogenizer with $0.5 \mathrm{ml}$ of distilled water, and a final volume of 1.5 cc was homogenized in an ice bath. The incubation medium, containing $0.5 \mathrm{cc}$ of $0.2 \mathrm{M}$ trismalate buffer $(\mathrm{pH} 7.2)$ and $0.2 \mathrm{cc}$ of $0.005 \mathrm{M} \mathrm{ATP}$ sodium salt was warmed to $37^{\circ} \mathrm{C}$, and $0.5 \mathrm{cc}$ of the homogenate was added. The contents of the tube were mixed immediately and incubated for 30 minutes at $37^{\circ} \mathrm{C}$. During incubation, tubes were shaken every 5 minutes. As a blank, an aliquot of the homogenate was incubated in the mixture lacking only ATP. The reaction was stopped by the rapid addition of $0.3 \mathrm{cc}$ of cold $25 \%$ trichloroacetic acid. After centrifuging, $1 \mathrm{cc}$ of the supernatant was taken for the estimation of inorganic phosphate by the method of Allen (Allen, R. J. L., 1940). ATPase activity was expressed as $\gamma \mathrm{P} / 10^{6}$ cells $/ 30$ minutes. Magnesium ion was not added to the incubation mixture as an activator, because the NaF used is a chelating agent of magnesium. 


\section{RESULTS}

\section{The Effect of Continuous Exposure to Various Concentrations of NaF on Synchronized Divisions}

Cells were cultivated continuously in various concentrations of $\mathrm{NaF}$ immediately after the heat-treatment. Observations were made for 320 minutes $\left(5^{1 / 3}\right.$ hours $)$. Three concentrations of $\mathrm{NaF}$ were selected which showed different effects on the synchronized divisions $(0.005 \mathrm{M}, 0.01 \mathrm{M}, 0.03 \mathrm{M})$. The results are illustrated in addition of agent (control) exhibited 3 synchronous divisions within the experimental period. Division maxima appear at 75 minutes, 190 minutes and 310 minutes after the heat-treatment, and they have fission indices of about $80 \%, 40 \%$ and $10 \%$ respectively. When heattreated cells are transferred to inorganic medium just after the heat-treatment (curve II), the 1 st and 2 nd synchronous divisions are observed at 75 minutes (fission index : $80 \%$ ) and 190 minutes (fission index : about $40 \%$ ) after the end of heat-treatment, but the $3 \mathrm{rd}$ division does not occur in this strain. In the presence of $0.005 \mathrm{M} \mathrm{NaF}$ (curve III), the 1 st and 2 nd synchronous divisions are scarcely influenced by the inhibitor: maximum division indices are much the same as those of control, however, the times of the division maxima are delayed 2 to 3 minutes at the first division and about 20 minutes at the second. In the case of $0.01 \mathrm{M} \mathrm{NaF}$, the 1 st synchronous division is

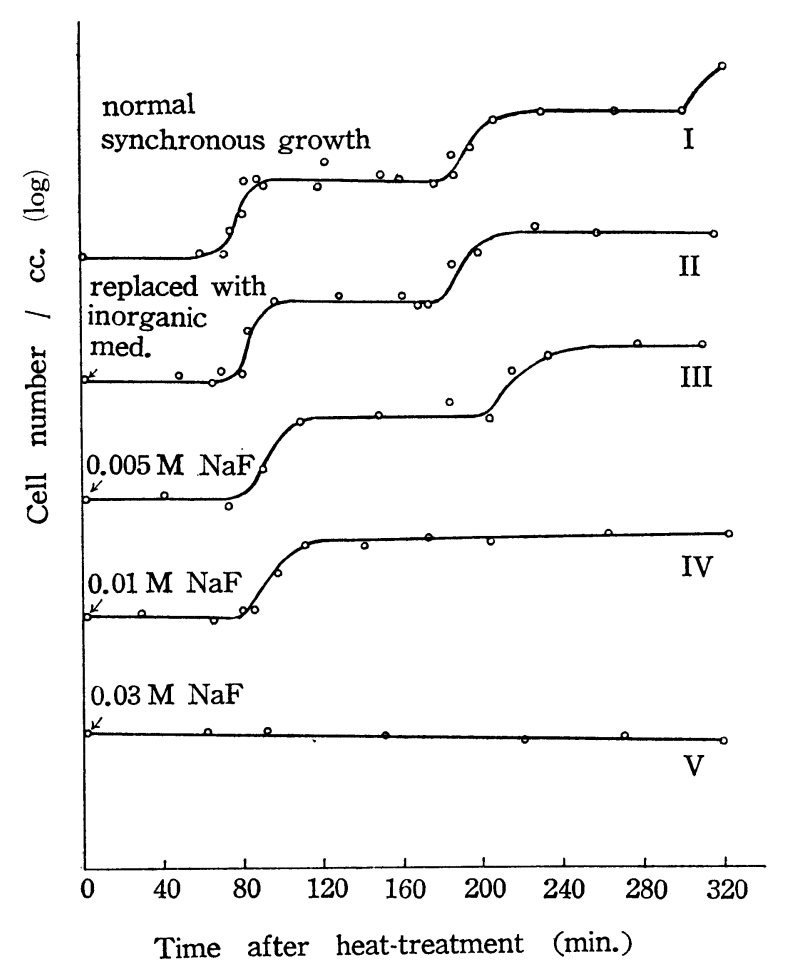

Fig. 2. Effects of continuous exposure to varying concentrations of $\mathrm{NaF}$ on synchronous divisions. Increases in cell number are plotted against time after heat-treatment. 
carried out normally. The maximum division index is nearly $80 \%$, and it appears at 80 minutes after the heat-treatment; however the 2 nd synchronous division is completely suppressed. In the case of $0.03 \mathrm{M} \mathrm{NaF}$, synchronous division is completely suppressed, but very few dead cells are found during the observation period.

Sensitivity Curve (The effect of short exposure to $0.03 \mathrm{M} \mathrm{NaF}$ )

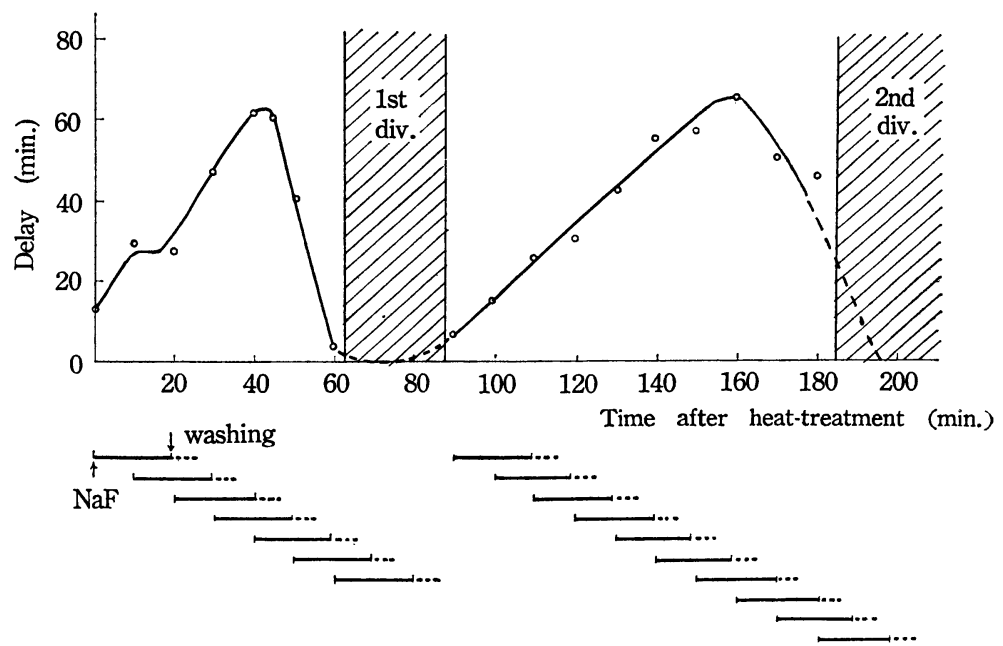

Fig. 3. Sensitivity curve of heat-treated cells exposed for 20 minutes to $0.03 \mathrm{M}$ $\mathrm{NaF}$ at various growth phases. Sensitivity is represented by delayed time of synchronous division after exposure. The abscissa gives the time at which $\mathrm{NaF}$ treatment was begun. Delay refers to the next division only.

\section{The Effect of Short Exposure to O.O3 M NaF on Synchronous Divisions}

Cells treated to induce synchronous divisions were exposed at various ages, to 0.03 $\mathrm{M} \mathrm{NaF}$ for 20 minutes, and then transferred to inorganic medium by 3 washings. The delays observed before reaching division maxima were plotted against the age of the cells at the time of exposure to the agent (Fig. 3).

During the first 45 minutes and after the 1 st division, there are gradual increases of sensitivity to $\mathrm{NaF}$. At approximately 45 minutes and 160 minutes there are sharp decreases in sensitivity followed by low sensitivity period for 30 minutes immediately preceeding the first and second division maxima (at 75 and 190 minutes). The changes of the sensitivity to $\mathrm{NaF}$ show a periodicity concomitant with the cell life cycle. Maximum delays were 62 minutes found at 30 minutes before the first division and 65 minutes at about 35 minutes before the second division.

\section{The Effect of Continuous Exposure to $0.01 \mathrm{M} \mathrm{NaF}$ at Various Ages after Heat-treatment on 2nd Synchronous Division}

The cells treated by the usual temperature cycles were exposed to $0.01 \mathrm{M} \mathrm{NaF}$ at various ages from 0 to 320 minutes after the treatment. Increase in cell number after addition of the agent is illustrated in Fig. 4. Inhibitors were added at 0,30 and 60 
minutes after the heat-treatment (before appearance of the 1 st division); and between the two divisions at 90,140 and 185 minutes (curves I-VI respectively). In the curve VII, the cells were exposed to the agent at the end of heat-treatment and tarnsferred to an inorganic medium at the end of the 1 st division (90 minutes after the heattreatment).

As seen in the figure, the 2 nd division is completely suppressed by adding the agent immediately after the heat-shock, however, the 2 nd divisions in the other cases are not completely suppressed. Dividing cell numbers in the 2 nd division are clearly increased in proportion to the age at which the cells are exposed to the inhibitor (curves II-VI); but the delays of the division maxima are not always related to the ages. Curves IV and VII represent two separate portions of the exposure to $\mathrm{NaF}$ given the cells in curve I. In both cases, the 2 nd synchronous divisions are exhibited, however, the division maxima are markedlp delayed in comparison to ordinary synchronous division. Complete suppression of the 2 nd division in curve I may be caused by the additive effect of the two exposures of curves IV and VII.

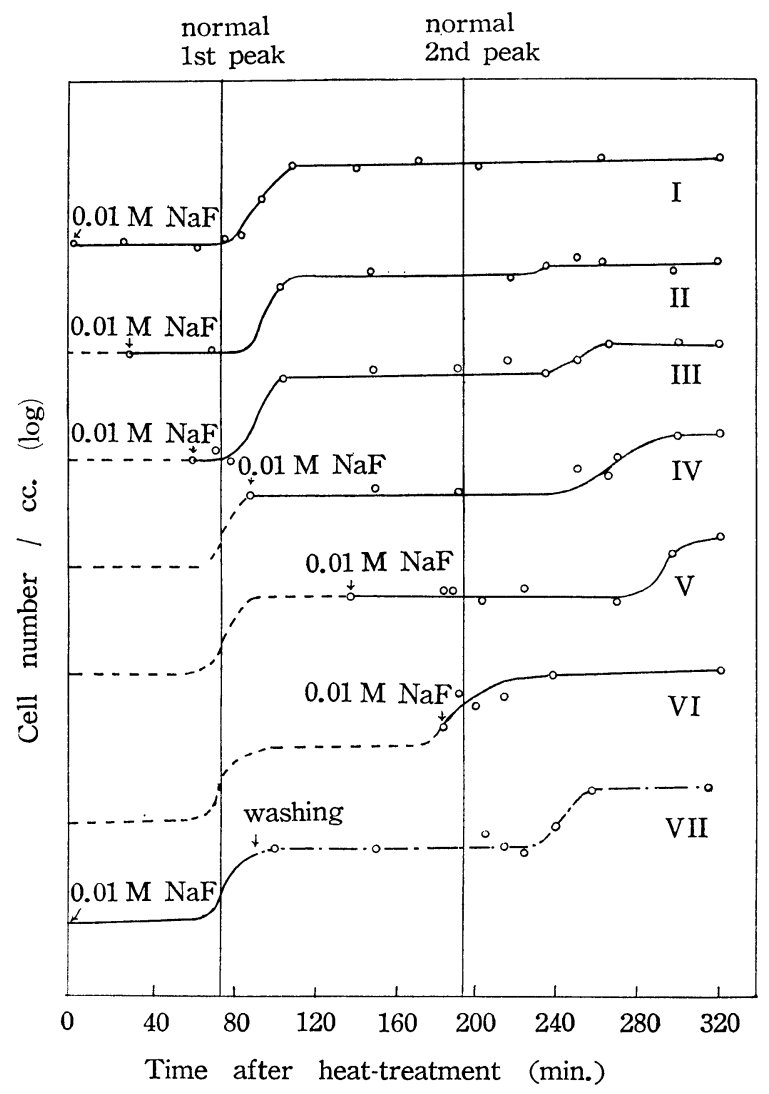

Fig. 4. Synchronous growth after exposure to $0.01 \mathrm{M} \mathrm{NaF}$ at various ages. The solid line represents cell counts in cultures containing the agent, and the broken line represents cell counts in ordinary cultures. In curve VII, the culture was washed and transferred to inorganic medium after exposure to $\mathrm{NaF}$. 


\section{The effect of NaF on the ATPase Activity of Synchronized Cells}

During the heat-treatments, the ATPase activity of the cells increased continuously and at the end of the treatment, average activity per $10^{6}$ cells is about 2.2 times that in log phase. But there is no increase of specific activity, since dry weight and volume of the cells during the heat-treatment also increased by about $2.2-2.4$ times their values in log phase. ATPase activity per cell during synchronous growth (control) is shown in Fig. 5. ATPase activity continues to increase slightly up to 15 minutes then decreases gradually, and at 30 minutes it begins to increase sharply again and reaches its maximum

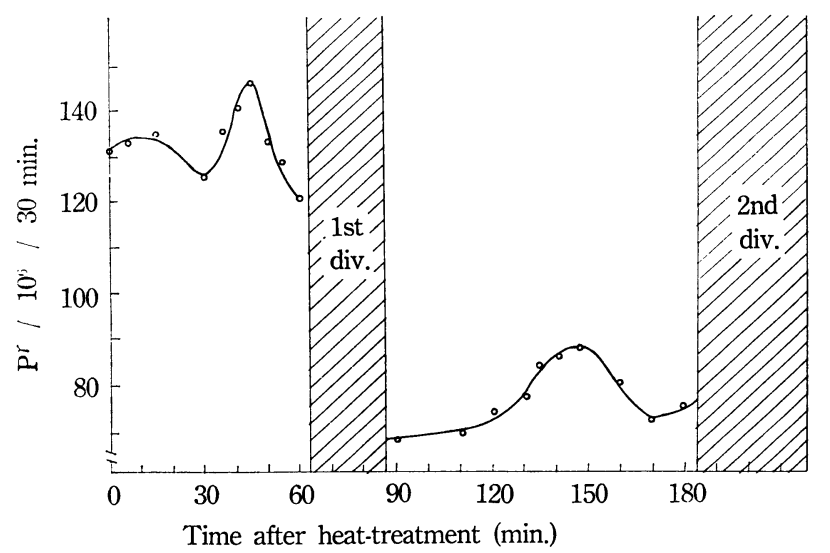

Fig. 5. ATPase activity in ordinary synchronous divisions. The ordinate represents ATPase activity per cell.

value at 45 minutes ( 30 minutes before the 1 st division maximum). Before the 2 nd division, maximum activity occurs at about $145-150$ minutes. The activity curves show another periodicity of the cell life cycle. ATPase activity per cell after the 1 st division is about half that before division. However, levels of activity per dry weight or volume in the first ands econd interdivisional periods are much the same.

As mentioned previously, different concentrations of $\mathrm{NaF}$ had different effects on synchronized division. Measurements of the enzymatic activity were performed in the cases where synchronous division was exhibited (divisions in ordinary synchronized cultures, in cultures transferred to inorganic medium at the end of heat-shock, in cultures exposed to $0.005 \mathrm{M} \mathrm{NaF}$ and the 1 st division of cultures exposed to $0.01 \mathrm{M}$ $\mathrm{NaF}$ ). Measurements were also performed where synchronized division was completely inhibited (the 1 st division in cultures exposed to $0.03 \mathrm{M} \mathrm{NaF}$, and the 2 nd division in cultures exposed to $0.01 \mathrm{M} \mathrm{NaF}$ ). Changes of ATPase activity following heat-treatment in four of the above cases are illustrated in Fig. 6 . When cells treated to produce synchronous divisions were transferred to inorganic medium at the end of heat-treatment (one of the controls), the enzymatic activity decreases gradually during the first 30 minutes, then it suddenly increases to a maximum at 45 minutes. As in the ordinary synchronous culture division maximum is achieved at 75 minutes.

In cultures exposed to $0.01 \mathrm{M} \mathrm{NaF}$, the changes of ATPase activity are very similar to those of cultures in inorganic medium; however, the culminating peak of activity 


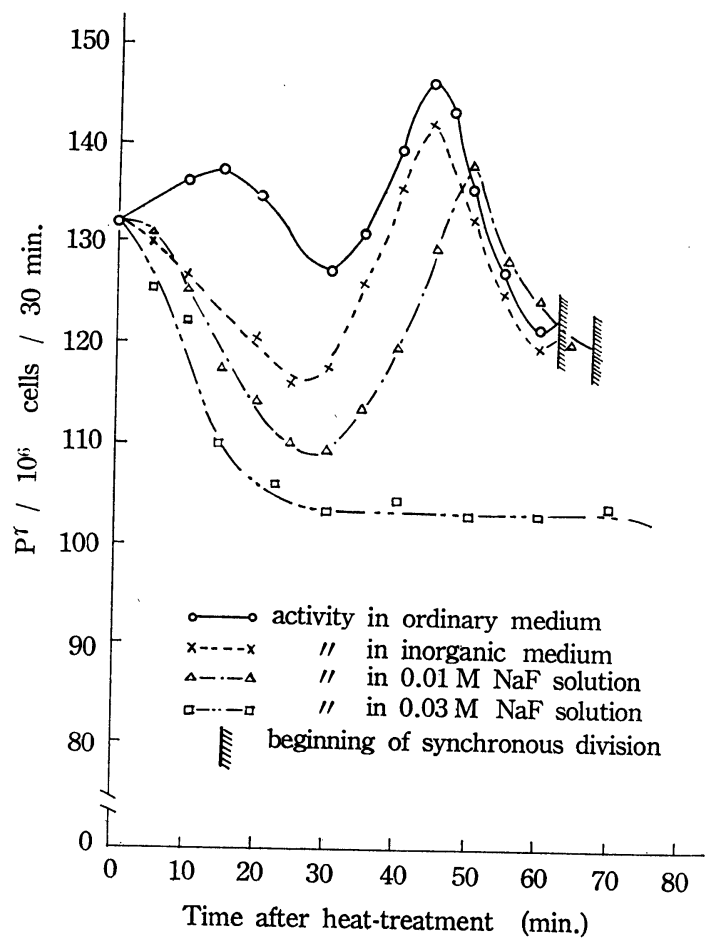

Fig. 6. ATPase activities during the first interdivisional period in cells under culture conditions regulated with $\mathrm{NaF}$. The ordinate represents activity per cell.

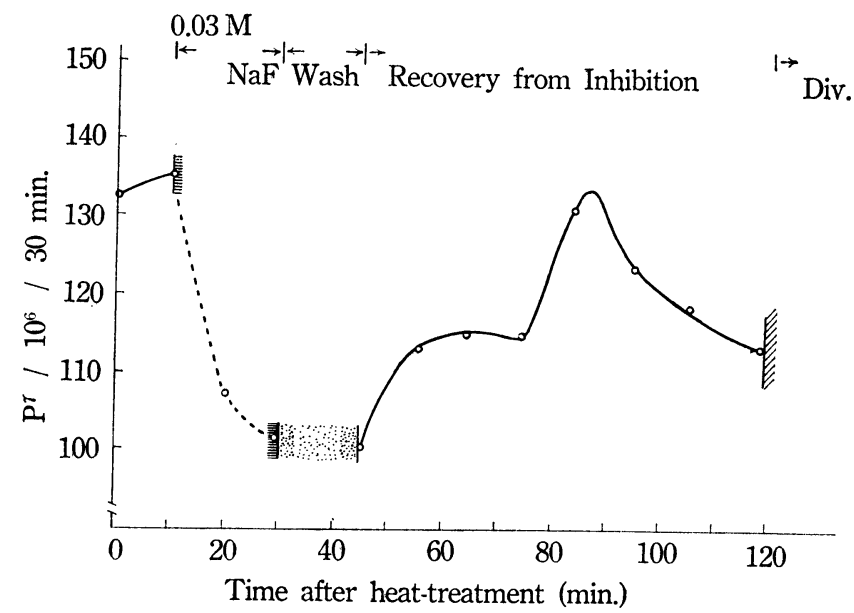

Fig. 7. Effects of short exposure to $0.03 \mathrm{M} \mathrm{NaF}$ at 10 minutes after heat-treatment on ATPase activity in synchronous division. The ordinate represents activity per cell. 
always appears at 50 minutes is a 5 minutes delay in comparison with controls. Division maximum is also delayed 5 minutes. The peak activity is always $3-6 \%$ lower than that of controls. In cultures exposed to $0.03 \mathrm{M} \mathrm{NaF}$, ATPase activity decreases during the first 30 minutes and then remains constant for nearly one hour. If the division is completely suppressed, no peak of enzymatic activity is observed at any time. The level of ATPase remains constant at $70-75 \%$ of the maximum in the controls (about $77 \%$ of the maximum in cultures containing $0.01 \mathrm{M} \mathrm{NaF}$ ). The results obtained indicate that the enzymatic activities always culminate 30 minutes before the next division maxima, but they remain constant when the divisions are suppressed.

The time relations between the appearance of the enzymatic peak and the division maximum were investigated in detail on division recovered after short exposure $(20$ minutes) to $0.03 \mathrm{M} \mathrm{NaF}$ at various ages. Regardless of when the division maxima occured, the peaks of ATPase activity regularly proceeded them by about $30-40$ minutes. This indicates that the time of the peak is closely connected with that of the next division maximum. A typical experiment is shown in Fig. 7. The cells were exposed to $0.03 \mathrm{M} \mathrm{NaF}$ for 20 minutes at 10 minutes after the heat-treatment. During exposure, the enzymatic activity decreases markedly, however, it soon rises and remains constant for about 30 minutes after washing, then rises to a peak at about 85-90 minutes after the heat-treatment. Meanwhile, the maximum division index is observed at about 125 minutes. The interval between activity maximum and division maximum may be estimated as $35-40$ minutes. However, there is a tendency for the interval to be delayed slightly when the cells are exposed to the concentrated $\mathrm{NaF}$ solutions.
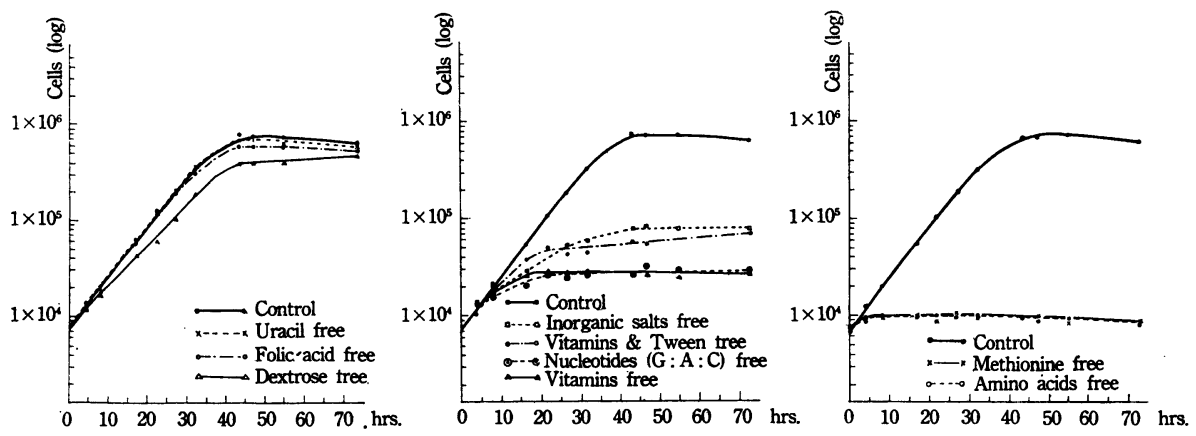

Fig. 8-10. Growth curves in some nutrient- or nutrients-free synthetic media. Curves are started at the time when log phase cells in normal growth are transferred to deprived media. Vitamins-free indicates a medium from B-I, B-II and B-III; and vitamins and tween-free indicates a medium free from B-II and B-III (cf. Table 1).

\section{Growth in Some Media Deprived of Specified Nutrients}

In order to investigate the growth in limiting nutrients for each cell cycle and the pool sizes of some essential nutrients, log phase cells grown in synthetic medium were transferred to one of several media deprived of specified nutrients and growth behavior in those media was observed. Media deprived of each main group or single nutrient of the nutritional factors were employed (cf. Table 1). Though each nutrient is indispensable for long term growth and division, effect of the absence of each is not revealed immediately after transfer. The behaviors of growth in various nutrients- 
deprived media may be divided into 3 types (Fig. 8-10).

In uracil-, folic acid-or dextrose- free media, growth is little influenced and is much the same as that of the control (Fig. 8). In inorganic salts-, nucleotides- or vitaminsfree media, the cells are able to divide 1 to 4 times at the beginning, but soon cease (Fig. 9). When log phase cells are transferred to animo acids- or simply methionine free media, most of the cells $(70 \%$ of the total) are prevented from entering division cycle (Fig. 10). Table 2 indicates the increase in cell numbers and the frequency of division during the period from transfer to the stationary phase in the nutrient-deprived media.

Table 2. The increase in cell number and frequency of division during culture in specified nutrient- or nutrients-free synthetic medium.

\begin{tabular}{|c|c|c|c|c|c|}
\hline \multirow{2}{*}{ Medium } & \multicolumn{2}{|c|}{ Cell number } & \multirow{2}{*}{$\mathrm{B} / \mathrm{A}$} & \multicolumn{2}{|c|}{ Frequency of division } \\
\hline & A : initial & B : stationary & & $2 \mathrm{x}=\mathrm{B} / \mathrm{A}$ & $(\mathrm{x})$ \\
\hline Control (complete) & $7.25 \times 10^{3}$ & $7.0 \times 10^{5}$ & 96.5 & 6.6 & \\
\hline Uracil free & $7.25 \times 10^{3}$ & $7.0 \times 10^{5}$ & 96.5 & 6.6 & \\
\hline Polic acid free & $7.25 \times 10^{3}$ & $5.5 \times 10^{5}$ & 69.0 & 6.1 & \\
\hline Dextrose free & $7.25 \times 10^{3}$ & $3.9 \times 10^{5}$ & 53.7 & 5.75 & \\
\hline Inorganic salts free & $7.25 \times 10^{3}$ & $7.9 \times 10^{4}$ & 10.9 & 3.46 & \\
\hline Vitamins \& Tween free & $7.25 \times 10^{3}$ & $5.5 \times 10^{4}$ & 7.6 & 2.95 & \\
\hline Nucleotides ( $\mathrm{G}: \mathrm{A}: \mathrm{C})$ free & $7.25 \times 10^{3}$ & $2.6 \times 10^{4}$ & 3.6 & 1.85 & \\
\hline Vitamins free & $7.25 \times 10^{3}$ & $2.6 \times 10^{4}$ & 3.6 & 1.85 & \\
\hline Amino acids free & $7.25 \times 10^{3}$ & $9.45 \times 10^{3}$ & 1.3 & \multicolumn{2}{|c|}{$\begin{array}{l}0.37 \\
\text { One division } \\
(30 \% \text { of total cells })\end{array}$} \\
\hline Methionine free & $7.25 \times 10^{3}$ & $9.45 \times 10^{3}$ & 1.3 & & \\
\hline
\end{tabular}

Vitamins-free indicates a medium free from B-I, B-II and B-III : and tween-free indicates a medium free from B-II and B-III (cf. Tabel 1).

In the first group, the cells can divide several times and increase to 50-100 times the initial number. Therefore, it is suggested that they can divide normally even if the amount of the nutrient in the cell decreases by a factor of fifty to one hundred. In the second group, all log phase cells including daughter cells can divide one or more times. In the third group, the initial population density rises to a stationary phase about 1.3 times of the original number. This increase represents the division of only $30 \%$ of the total cells in log phase. The value of the increase $(B / A=1.3)$ coincides perfectly with that of the log phase cells transferred complete medium to inorganic medium. Moreover, it is to be noted that the cell growth in methionine-free medium is the same as that in medium deprived of all amino acids.

\section{Rhythm in Morphological Changes without Division}

Synchronous divisions were induced at the same time (75 minutes), whether the cells were treated by the heat-shock in the chemically defined medium of the nutrientdeprived media, however, only $30 \%$ of the total cells divided synchronously in the amino acid-free medium; when the cells are transferred to the deprived media at the begining of heat-treatment.

On the other hand, behaviors of the synchronous division were different depending 
upon each medium, when the cells are transferred to the nutrient-deprived media at 5 hours before the heat-treatment and then exposed to the temperature-shock in those media. In uracil, folic acid of dextrose-free medium, the level and the time of appearance of synchronous division maxima were much the same as those in the complete medium. With the salts, vitamins or nucleotides-free medium, synchrony was somewhat lost but the time of the division maximum was not influenced. In particular, the degree of the synchrony was very low in the nucleotides-free medium. In the media lacking amino acids or only methionine, no division was observed after the heat-treatment, but some morphological changes occured synchronously at the time of division maximum in a normal culture.

The shape of Tetrahymena pyriformisis usually pyriform as its name implies,

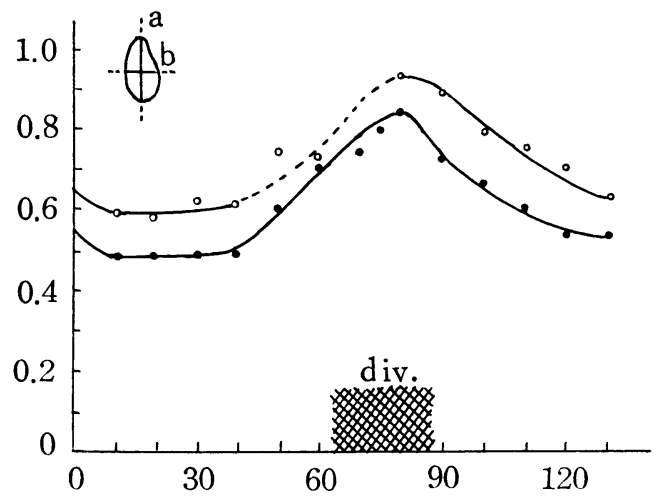

Fig. 11. Divisionless rhythmic changes of cell shape after heat-treatment in amino acids-free medium. The average values of axial ratios $(a / b)$ in many cells are plotted against time after heat-treatment, where $a$ and $b$ are minor and major axes of the cell respectively.

approximately an ellipsoid of revolution with a slightly pointed anterior end. When the cells are cultivated in amino acids-free medium, the shapes of most cells become slender because of the arrest of growth. During the heat-treatment in the medium, their shapes and sizes did not change at all ; however, these slender cells bacame rather spherical synchronously but without division at 80 minutes after the heat-treatment, and then regained their forms to former appearance at 120-135 minutes. The morphological rhythm of the heat-treated cells in amino acids-free medium is illustrated in Fig. 11. In order to follow the morphological changes, the minor axis (a) and major axis (b) in many cells were measured at various ages after the heat-treatment. In the figure, mean values of the ratios of major axis to minor $(a / b)$ are plotted against time after the heat-treatment. The most spherical form occurs at 80 minutes after the heattreatment which corresponds to the separation time of synchronous division in the ordinary medium. In the control, the shape of the daughter cells immediately after division is almost spherical, but it becomes gradually pyriform with time. The rhythm induced by temperature-shock is not so pronounced in cells transferred to inorganic medium at 5 hours prior to the treatment. The rhythm can be induced by the addition of nucleotides, vitamins and inorganic salts to the medium during the experiment. 


\section{DisCUSSIONS}

\section{Effect of exposure to NaF on synchronous divisions}

Temperature-induced synchronous divisions can be suppressed by adding diverse inhibitors of oxidative phosphorylation system (Hamburger, K. and Zeuthen, E., 1957 ; Watanabe, Y., Ishii, K. and Toyoshima, Y., in preparation; Zeuthen, E., 1958). In particular, behaviors of the synchronous divisions are determined by exposure to 0.005 $\mathrm{M}, 0.01 \mathrm{M}$ and $0.03 \mathrm{M} \mathrm{NaF}$ immediately after the heat-treatment. Varying concentrations of other inhibitors (i.e., $\mathrm{KCN}, 2$, 4-dinitrophenol, $\mathrm{NaN}_{3}$, iodoacetate, etc.), did not yield such clear cut results as $\mathrm{NaF}$.

As shown in Fig. 2, the first two synchronous divisions occur as usual in the presence of $0.005 \mathrm{M} \mathrm{NaF}$, but they are completely suppressed by $0.03 \mathrm{M} \mathrm{NaF}$; and such interesting effects are obtained as a normal first synchronous division followed by a second division that is completely suppressed in the presence of $0.01 \mathrm{M} \mathrm{NaF}$. It has been indicated that the concentration of the agent necessary to inhibit the 1 st synchronous division completely is three times of that required to inhibit the 2 nd division. Differences of the effects of the agent have sometimes been attributed to differences in sensitivity to it within the first and second interdivisional periods. However, the sensitivity curve obtained by short exposure to concentrated $\mathrm{NaF}$ (Fig. 3) does not show signiffcant differences between the two periods.

The 2nd synchronous division may be exhibited in spite of exposure to $0.01 \mathrm{M}$ $\mathrm{NaF}$ from the end of the 1 st division to the end of the 2 nd division, but the time of the 2 nd division is markedly delayed by the exposure (Fig. 4, curve IV). It is also evident that the time of the 2 nd synchronous division is markedly delayed (more than 60 minutes) by exposure to $0.01 \mathrm{M} \mathrm{NaF}$ from the end of heat-treatment to the completion of the 1 st division (Fig. 4, curve VII). In this case, the 1 st division is only slightly influenced by the presence of $0.01 \mathrm{M} \mathrm{NaF}$.

These results suggest the possibility that the 2 nd division perhaps depends upon not only the metabolism in the 2 nd interdivisional period but also that of the 1 st interdivisional period. Consequently, metabolic activity occuring during one generation probably include both indispensable and dispensable activities for the following pivision.

The above characteristic of cellular metabolism has been also found in the following evidence (Watanabe, Y., 1962). When the cells are transferred to inorganic medium near the end of heat-treatment, they go through the first two synchronous divisions as usual with no increase in size and generation time; and after the end of the 2nd division average size of these cells is about one third that of cells in ordinary synchronous culture (proteose-peptone) at the time. In ordinary synchronous culture, considerable growth can be observed during the first and second interdivisional periods, however, the growth is not related directly to the first two synchronous divisions. After the end of the 2 nd synchronous division, the cells are not able to divide further in an inorganic medium, while they are able to increase in number continuously in the proteose-peptone medium. Thus it may be assumed that the growth occuring during the first two interdivisional periods in the ordinary culture is not necessary for the first two divisions, but may be indispensable for the preparatory process of further divisions. Therefore, if we measure only the total amounts of a compound within one cell cycle in ordinary culture, it will be impossible to determine the vital connection between cell'division and amount of the compound. 


\section{ATPase Activity and Cell Division}

In order to reveal the close relationship between ATPase activity and cell division, the enzymatic activities were estimated on heat-treated cells cultivated in the presence of varying concentrations of $\mathrm{NaF}$.

The enzymatic activities always culminate at about 30 minutes before division maxima when synchronous divisions appear. The activities remain constant and do not reach a peak when divisions are completely suppressed (Fig. 6). Moreover, the time of maximum enzymatic activity may be closely related to the time of the following division. As far as the first synchronous division is concerned, the interval between activity peak and division maximum is estimated as 30 minutes. For further investigation of this time relation, ATPase activities were measured in detail on the 1 st divisions recovered after short exposure ( 20 minutes) to $0.03 \mathrm{M} \mathrm{NaF}$ at various ages. Regardless of when the divisions occured, the peaks of the enzymatic activity regularly preceeded them by about $30-40$ minutes. However, it is to be noted that the intervals between activity peaks and division maxima are rather longer than those in the ordinary synchronized culture. This elongation of the intervals may be attributed to the pronounced elongation of the interdivisional period by exposure to the agent; however, the delays of activity and division peaks are not proportional to each other. It can be said that the interval between activity peak and division maximum is rather constant in comparison with the delay of synchronous division.

After confirmation of the vital connection between ATPase activity and cell division, the minimum activity indispensable for division can be estimated. For the first synchronous division, an estimate of the minimum activity for division may be obtained by subtracting the activity in the presence of $0.03 \mathrm{M} \mathrm{NaF}$ (minimum dosage for complete division suppression) from the activity in the presence of $0.01 \mathrm{M} \mathrm{NaF}$ (maximum infective dosage). From the activity curves shown in Fig. 6, it is evident that the changes of ATPase activity in both cases are very similar to each other for the first 30 minutes after the heat-treatment; however, the activity then increases progressively to a maximum at 50 minutes in the presence of $0.01 \mathrm{M} \mathrm{NaF}$, while it remains constant for nearly one hour in the presence of $0.03 \mathrm{M} \mathrm{NaF}$. The level of remaining in 0.03 $\mathrm{M} \mathrm{NaF}$ is estimated to be $77 \%$ of the activity maximum in $0.01 \mathrm{M} \mathrm{NaF}$. The activity indispensable for division is, therefore, only small fraction (23\%) of the maximum observed activity.

Similar evidence supporting the above results has been previously reported in Tetrahymena concerning the respiration related to division by Hamburger and Zeuthen (Hamburger, K. and Zeuthen, E., 1960). After comparing the oxygen uptake for synchronized and for log phase cells both in proteose-peptone and in inorganic media, two fractions of the respiration are clearly distinguished: one consisting of $30 \%$ of total activity that can fully support cell division, and another of $70 \%$ which is related to growth and unnecessary for the next division. Thus, it is concluded that the close relationship between division and ATPase activity or respiration can be demonstrated only when the activity indispensable for cell division can be distinguished from the total activity.

\section{Uptake of Nutrients and Cell Division}

Most of log phase cells (about $70 \%$ ) in proteose-peptone and synthetic media are 
prevented from entering division by transfer to an inorganic medium (Hamburger, $\mathrm{K}$. and Zeuthen, E., 1957 ; Prescott, D. M., 1960 ; Watanabe, Y., Ishii, K. and Toyoshima, Y., in preparation). It has therefore been thought that unlike fertilized eggs they do not possess the potential ability for division, and are able to divide by the uptake of nutrients in every division. Of course, this does not mean that cell division must occur when the amounts of all cellular components become twice those of the daugher cells. Although the cells itself cannot divide in the inorganic medium, some of the components might be stored large enough amounts to permit several cell divisions without any further uptake.

The results derived from the studies on the growth in the nutrients deprived media indicate that all nutrient factors except amino acids are present in considerable amounts in the log phase cells or even in the daughter cells (Figs. 8-10, and Table 2). In particular, when log phase cells are washed and transferred to folic acid or uracil-free medium, they are able to increase normally for a long time in spite of the marked decrease in amount of these factors. As seen from Table 1, thymine or thymidine has not been put on the table as an essential nutrient. It has been shown in Tetrahymena that thymine can be synthesized from non-pyrimidine precursors (but neither by methylation of uracil, nor by transformation of orotic acid) and that folic acid must function in one or more of the steps leading to thymine synthesis (Kidder, G. W. and Dewey, V. C., 1951). A similar result has been previously reported by Kidder and Dewey (Kidder, G. W. and Dewey, V. C., 1951) who find that there is enough storage of folic acid for almost optimum growth during the first transfer into folic acid-free medium, however, subsequent transfers fail unless folic acid is added. Estimations of DNA content during the growth in folic acid-free medium have revealed that DNA content per culture increased exponentially as in complete medium, and DNA content per cell remained constant during the course of growth (Watanabe, Y., to be published).

While, the transfer of log phase cells to uracil-free medium has no immediate effect (for about 20 hours) on multiplication and protein synthesis, RNA content per culture remains constant from soon after transfer and the amount of RNA per cell decreases with each division (Lederberg, S. and Mazia, D., 1960). This observation has been repeated (Watanabe, Y., to be published) although the amount of RNA per culture continued to rise for a longer time after transfer than previously reported.

When cell multiplication occurs in folic acid or uracil-free media, large surplus stores of the nutrient or its derivatives probably existed in the initial log phase cells. Therefore, it should always be remembered that the biochemical necessities for division are not brought to light by measuring the changes in total amount of each cellular component from one division to the next. Prescott (Prescott, D. M., 1961) has given the same opinion from the studies on synthesis patterns of DNA, RNA and protein throughout the cell life cycle.

\section{Specific Protein Synthesis for Division}

In Tetrahymena, there can be no doubt that one nutrient factor which must be taken from the exogenous environment for every division is a particular group of amino acids (Fig. 10, and Table 2). As mentioned previously, about $70 \%$ of the log phase cells are prevented from entering division when they are transferred to an inorganic, amino acids-free or methionine-free medium. This suggests that only the cells which have reached a certain proximity to division under the previous culture conditions, in 
other words, the cells which have completed $70 \%$ (147 minutes) of their 210 minute generation time, are capable of dividing without any uptake of amino acids. The critical time (147 minutes) is about 45 minutes before the beginning of cytokinesis (193 minutes).

As the DNA synthesis is restricted to the first half of interphase (McDonald, B. B., 1958 ; Prescott, D. M., 1960), the cells passing through more than 105 minutes probably have double the amonut of DNA in the daughter cells. But the cells between 105 and 146 minutes after division can not divide without taking up amino acids from the culture medium and subsequently synthesizing a specific protein, in spite of the doubling of DNA. Since the simultaneous syntheses of DNA and histones have been demonstrated clearly in various organisms (Alfert, M., 1958; Bloch, D. P., 1955, Gall, J. G., 1959 ; Prescott, D. M. and Kimball, R. F., 1961 ; Prescott, D. M., 1962), this specific protein synthesis is probably not concerned with histones, but may be concerned with structural protein necessary for cytokinesis. The approximate time of this protein synthesis can be estimated from the endogenous pool size of free amino acids. In Tetrahymena, it has been found that the amino acid pool size is nearly constant even under different growth conditions and the nitrogen content of free amino acids is about $13 \%(12.6-15 \%)$ of that in the total protein (Scherbaum, O. H., James, T. W. and Jahn, T. L., $1959 \mathrm{~b}$ ). Consequently, the specific protein synthesis for division probably occurs close to the period of maximum activity of the oxidative phosphorylation system, if the protein is synthesized from free amino acids in the pool when the cells were transferred from complete medium to amino acids deprived medium. The necessity of protein synthesis for division may also be seen in the effect of ethionine (Watanabe, Y., to be published ; Zeuthen, E., 1961 b) or p-fluorophenylalanine (Zeuthen, E., $1961 \mathrm{a}$; Zeuthen, E., 1961 b) on synchronous divisions.

\section{Factors Leading to the Organization of Division}

From the results of the present experiments, it is evident that the ATPase activity for division culminates at about 30 minutes prior to the middle stage of division, and the specific protein synthesis is supposed to take place concomitantly. Moreover, at about the same time, it has been shown that the amounts of nucleoside triphosphates including ATP, GTP etc. reach a peak (Plesner, P. E., 1958); that the turnover rate of $\mathrm{P}^{32}$ (Hamburger, $\mathrm{K}$. and Zeuthen, E., 1960) and rate of respiration (7.euthen, E., 1953 ; Zeuthen, E. and Scherbaum, O., 1954) are culminated; and that the sensitivity to 2, 4-dinitrophenol (Hamburger, K. and Zeuthen, E., 1957), NaF (Fig. 3), p-fluorophenylalanine (Zeuthen, E., $1961 \mathrm{~b}$ ), and other inhibitors of oxidative phosphorylation system (Zeuthen, E., 1958) or analogs of amino acids (Watanabe, Y., to be published, Zeuthen, E., 1961 b) is highest. Similarly the acid-soluble phosphates are perhaps polymerized to insoluble polyphosphates at around this time (Scherbaum, O. H., Londerback, A. L. and Jahn, T. L., 1959 a ; Scherbaum, O. H., 1960). This may indicate that insoluble polyphosphates play a key role in producing division conditions, since the polyphosphates appear to be unique in showing no increase in amount during the heat-treatment. From these results it seems unlikely that the cell division is accomplished by a direct reaction between contractile protein (like muscle protein) and ATP in the furrowing region.

Two prominent metabolic activities (activation of oxidative phosphorylation and specific protein synthesis) probably act coordinately in order to produce the division 
conditions; because if either of them is blocked selectively, the cells are completely prevented from entering division. As an example of the selective inhibition of oxidative phosphorylation, cells being treated by the temperature-shock or by inhibitors of that system are recalled. Cell divisions are arrested so long as the treatment is continued, although some protein synthesis takes place. On the contrary, when the cells are treated by temperature-shock in amino acids-free medium, they are prevented from entering division due to the deprivation of materials for protein synthesis during and after the heat-treatment, but morphological changes closely related to division appear at 80 minutes after the heat-treatment (Fig. 11). This divisionless morphological rhythm may be induced by the action of the oxidative phosphorylation necessary for subsequent cell division.

Now it is tempting to suggest that the final biochemical step playing a key role in the appearance of the furrowing may be achieved mainly by cooperation of activation of oxidative phosphorylation and specific protein synthesis, followed by macromolecular organization necessary to produce division conditions.

\section{SUMMARY}

1. The present article was designed to investigate the metabolic processes indispensable for cell division in Tetrahymena pyriformis $\mathrm{W}$ and to clarify some characteristics of these activities, in an attempt to demonstrate a generalized mechanism of cell division.

2. Temperature-induced synchronized divisions are completely suppressed by addition of $0.03 \mathrm{M} \mathrm{NaF}$, while they are scarcely influenced by addition of $0.005 \mathrm{M} \mathrm{NaF}$ at the end of heat-treatment. An interesting inhibition is observed when cultures are exposed to $0.01 \mathrm{M} \mathrm{NaF}$ at the end of heat-treatment : the first synchronous division is exhibited as normal, while the second is completely suppressed. The biological meaning of the different concentrations of the agent resulting in complete inhibition of the 1 st and 2 nd synchronous divisions may be that some activities occurring within one generation are related not only to the next division but also to further divisions, according to the results derived from the studies on effects of short or long exposure to $0.03 \mathrm{M}$ or 0.01 $\mathrm{M} \mathrm{NaF}$ on cells of various ages.

3. ATPase activities were measured in synchronized cells exposed to $0.005 \mathrm{M}$, $0.01 \mathrm{M}$ and $0.03 \mathrm{M} \mathrm{NaF}$. Regardless of when the divisions occur, peaks of ATPase activity regularly appear about 30-40 minutes prior to synchronous division maxima; on the contrary, pronounced culmination of the enzymatic activity does not appear at all when divisions are completely suppressed. ATPase activity indispensable for the succeeding division is estimated as only small fraction (about $23 \%$ ) of the total activity observed 30-40 minutes prior to synchronous division maximum.

4. Log phase cells grown in proteose-peptone or synthetic media are able to divide one or more times when they are transferred to synthetic media deprived of various groups of nutrients except amino acids. Log phase cells probably have stores of nutrients or their derivatives to a greater or lesser extent. This indicates that the total amount of a cellular component may not always be critical to the next division.

5. Most log phase cells $(70 \%$ of the total) are unable to divide when transferred to amino acids-free or methionine-free media. This indicates that only those cells which have passed through more than $70 \%$ (147 minutes) of one generation (210 minutes) are able to divide in the amino acids-free medium, the remainder must take up amino 
acids from the sources and synthesize a specific protein for cell division. The specific protein seems to be related to cytokinesis; and the critical point in its synthesis may take place approximately at the time when the oxidative phosphorylation system shows its greatest activity, since the pool of free amino acids in the cell at 147 minutes is sufficient to permit protein synthesis to continue until this time.

6. The relationship between oxidative phosphorylation and specific protein synthesis indispensable for division is discussed. Production of division conditions may be induced by cooperation of these two metabolic activities.

The work reported here was done under the auspices of Professor Tohru H. Abé. I wish to express my sincere gratitude for his warm encouragement and advice continuously given in the course of study. My thanks are also due to Drs. K. Ishii and F. Kanno for their helpful suggestions. I am indebted to Miss. Y. Toyoshima for her assistance in carrying out some of the experiments.

\section{REFERENCES}

AlfERT, M. (1958): Variations in cytochemical properties of Cell nuclei. Exper. Cell Res., Suppl. 6, 227-235.

Allen, R. J. L. (1940): The estimation of phosphorus. Biochem. J., 34, 858-865.

BLOCH, D. P. (1955): A microphotometric study of the syntheses of deoxyribonucleic acid and nuclear histone. J. Biophysic. and Biochem. Cytol., 1, 17-28.

CAMPBell, A. (1957): Synchronization of cell division. Bact. Rev., 21, 263-272.

Dewey, V. C., PArks, R. E., JR. \& Kidder, G. W. (1950) : Growth responses of Tetrahymena geleii to changes in the basal media. Arch. Biochem., 29, 281-290.

GaLL, J. G. (1959) : Macronuclear duplication in the ciliated protozoan Euplotes. J. Biophysic. and Biochem. Cytol., 5, 295-308.

Hamburger, K. \& ZeUthen, E. (1957): Synchronous divisions in Tetrahymena pyriformis as studied in an inorganic medium. The effect of 2,4-dinitrophenol. Exper. Cell Res., 13, 443-453.

HAMBurger, K. \& ZeUthen, E. (1960): Some characteristics of growth in normal and synchronized populations of Tetrahymena pyriformis. Compt. rend. Lab. Carlsberg., 32, $1-18$.

KIDDER, G. W. \& DEWEY, V. C. (1951) : In Lwoff, A., Biochemistry and Physiology of Protozoa. Vol. 1, p. 392. Academic Press, N. Y.

LEDERBERG, S. \& MAZIA, D. (1960) : Protein synthesis and cell division in a pyrimidine-starved protozoan. Exper. Cell Res., 21, 590-595.

MAZIA, D. (1961) : In Brachet, J. and Mirsky, A. E., The Cell. Vol. III, p. 77. Academic Press, N. Y. and London.

MCDONALD, B. B. (1958): Quantitative aspects of deoxyribo nucleic acid (DNA) metabolism in an amicronucleate strain of Tetrahymena. Biol. Bull., 114, 71-94.

Plesner, P. E. (1958): The nucleoside triphnsphate content of Tetrahymena pyriformis during the division cycle in synchronously dividing mass cultures. Biochem. et biophys. acta, 29, 462-463.

PRESCOTT, D. M. (1960) : Relation between cell growth and cell division. IV. The synthesis of DNA, RNA and protein from division to division in Tetrahymena. Exper. Cell Res., 19, 228-238.

PRESCOTT, D. M. (1961): The growth-duplictaion cycle of the cell. in Bourne, G. H. and Danielli, J. F., International Review of Cytology, Vol. 11, 255-282, Academic Press, N. Y. and London. 
Prescott, D. M. \& Kimball, R. F. (1961): Relation between RNA, DNA and protein syntheses in the replicating nucleus of Euplotes. Proc. Nat. Acad. Sc., 47, 686-693.

PRESCOTT, D. M. (1962) : Nucleic acid and protein metabolism in the macronucleic of two cilliated protozoa. J. Histochem. and Cytochem., 10, 145-153.

Scherbaum, O. \& ZeUtheN, E. (1954): Induction of synchronous cell division in mass cultures of Tetrahymena pyriformis. Exper. Cell Res., 6, 221-227.

Scherbaum, O. H., LONDERBACK, A. L. \& JAHN, T. L. (1959a) : DNA synthesis, phosphate content and growth in mass and volume in synchronously dividing cells. Exper. Cell Res., 18, 150-166.

Scherbaum, O. H., James, T. W. \& Jahn, T. L. (1959 b) : The amino acid composition in relation to cell growth and cell division in synchronized cultures of Tetrahymena pyriformis. J. Cellular Comp. Physiol., 53, 119-137.

Scherbaum, O. H. (1960) : Possible sites of metabolic control during the induction of synchronous cell division. Ann. N. Y. Acad. Sc., 90, 565-579.

WATANABE, Y. (1960): Arificially induced synchronous divisions in micro-organisms. (Rev. in Japanese). Biol. Sc. (Tokyo), 12, 63-71.

Watanabe, Y. (1962): Cell division and its metabolism. (Rev. in Japanese) Biol. Sc. (Tokyo), $14,55-62$.

WATANABE, Y., IshII, K. \& TOYOSHIMA, Y. : In preparation.

WATANABE, Y.: To be published.

ZEUTHEN, E. (1953) : Growth as related to the cell cycle in single-cell cultures of Tetrahymena pyriformis. J. Embryol. Exper. Morphol., 1, 239-249.

ZEUTHEN, E. \& SCHERBAUM, O. (1954): Synchronous divisions in mass cultures of the ciliate protozoan Tetrahymena pyriformis, as induced by temperature changes. Colston Papers, 7 , 141-156.

Zeuthen, E. (1958) : Artificial and induced periodicity in living cells. Advances in Biol. and Med. Phys., 6, 37-73.

Zeuthen, E. (1961 a): Synchronized growth in Tetrahymena cells. in Zarrow, M. X., Growth in Living Systems. p. 131, Basic Books, N. Y.

Zeuthen, E. (1961 b) : In Goodwin, T. W., and Lidberg, O., Biological Structure and Function, Vol. II, Cell division and Protein Synthesis. p.537, Academic Press. N. Y. and London. 